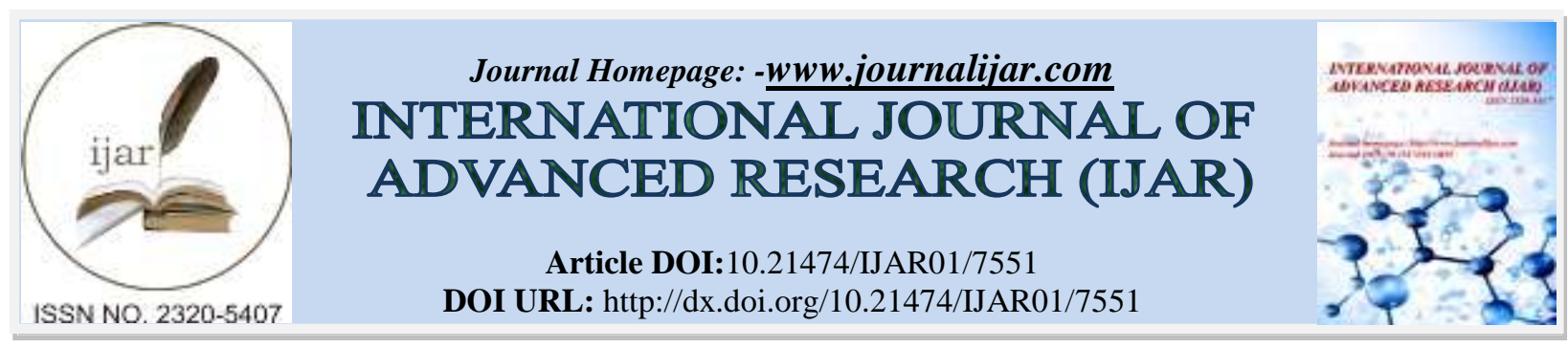

RESEARCH ARTICLE

\title{
EFFECT OF INTERMITTENT SUBGLOTTIC SECRETION DRAINAGE VS STANDARD ENDOTRACHEAL TUBE ON THE INCIDENCE OF VAP IN INTENSIVE CARE UNITS.
}

\author{
Anoopjit Kaur ${ }^{1}$, Prabhjot Saini ${ }^{2}$, Shivani Kalra ${ }^{3}$ and Dr. Rajesh Mahajan ${ }^{4}$. \\ 1. Nursing Tutor, DMCH College of Nursing, Ludhiana. \\ 2. Professor, DMCH College of Nursing, Ludhiana. \\ 3. Asstt. Professor, DMCH College of Nursing, Ludhiana \\ 4. Professor, Deptt. of Medicine, DMC and Hospital, Ludhiana.
}

\section{Manuscript Info}

Manuscript History

Received: 13 June 2018

Final Accepted: 15 July 2018

Published: August 2018

\section{Abstract}

Copy Right, IJAR, 2018,. All rights reserved.

\section{Introduction:-}

When a patient is mechanically ventilated, the invasive ventilatory support is provided via either a tracheostomy tube or an endotracheal tube ${ }^{1}$. The endotracheal tube (ET) bypasses the natural cough mechanism which helps to avoid aspiration of upper-airway secretions. These secretions then pool above the ET cuff and eventually can cause microaspiration and thus pneumonia ${ }^{2}$ which is known as Ventilator-associated pneumonia (VAP). VAP is the most frequently acquired infection by patients admitted in intensive care units (ICUs) that develops 48 hours or longer after mechanical ventilation. IDSA and ATS defines VAP as pneumonia that occurs $>48$ hours after the endotracheal intubation. ${ }^{3}$ It results from the invasion of the lower respiratory tract and lung parenchyma by microorganisms. Intubation compromises the integrity of the oropharynx and trachea and allows oral and gastric secretions to enter the lower airways ${ }^{4}$.VAP is associated with substantial morbidity and costs.

VAP is a complication in as many as $28 \%$ of patients who receive mechanical ventilation. The incidence of VAP increases with the duration of mechanical ventilation. ${ }^{4}$ The subglottic secretion drainage is also one of the few newly suggested preventive strategies for prevention of VAP in intubated patients. Endotracheal tubes with subglottic secretion drainage (incorporating a suction port above the cuff) have been shown to reduce the incidence of VAP by $50 \%$ but still it is not in common practice in ICUs in Indian settings.

As this study assess and compare the effect of intermittent subglottic secretions drainage (ISSD) and standard endotracheal tube (SET) on the incidence of VAP. The evidence thus generated from this study clearly help to select the effective ET that will help in reduction of VAP.

\section{Methods:-}

The study was conducted in selected Intensive Care Units (ICUs) of a tertiary care hospital. ICUs included medicine ICU, surgery ICU, neurosurgery ICU, pulmonary Critical Care Unit, trauma ICU, stroke ICU and emergency ICUs. The ICUs have 24-hours intensivist coverage. Routine nursing care was given to the admitted patients. VAP prevention protocol was being followed as a part of routine care. This observational (comparative) study was performed in a 1326 bedded tertiary care hospital having 111 bedded ICUs capacity in India, from September 2014 
-February 2015. Purposive sampling technique was used to draw sample. The institutional review board of the hospital approved the study. Written consent was obtained from the subjects or from their next of kin.

\section{Inclusion and exclusion criteria:-}

All the intubated patients older than 18 years with duration of mechanical ventilation $\geq 48$ hrs and were willing to participate were included in the study. Patients excluded were those admitted with community acquired pneumonia, came from other hospital with symptoms of VAP, were on tracheostomy tube, were re-admitted to ICU mechanical ventilator for $<48$ hours or were immunocompromised (like HIV or drug induced, in organ transplantation or on long term steroid therapy).

\section{Study population/ participants:-}

The target population included adult patients on mechanical ventilator admitted in ICUs. Depending upon the type of endotracheal tube the subjects who were mechanical ventilated, were divided into 2 groups i.e. group 1 (Intermittent subglottic secretion drainage ET) and group 2 (Standard ET). Total sample size was 130. It includedGroup 1- Intermittent subglottic secretion drainage group (ISSD) $(n=67)$ and Group 2- Standard endotracheal tube group $(\mathrm{SET})(\mathrm{n}=63)$.

\section{Data Collection and processing:-}

Data was collected regarding subject's profile including socio-demographic profile, clinical profile, modified CPIS and daily record sheet including the SAPS II by using the records and reports and the observation method to obtain the relevant information. (In the hospital ICUs, VAP bundle was being followed as part of daily routine care provided to ventilated patients). The subject's health parameters were recorded while on mechanical ventilators with any type of ET till extubation.

\section{Outcome measures:-}

VAP in our study is the pneumonia that had occurred after $48 \mathrm{hrs}$ of intubation and mechanical ventilation as assessed by the CPIS scale. The CPIS $\geq 6$ after 48 hours of mechanical ventilation till extubation was suggestive of VAP. Also, the early onset VAP has been defined as VAP that occurs within 4 days of the mechanical ventilation whereas late onset VAP develops at or after 5 days. ${ }^{7}$ Subjects were followed till discharge for the information regarding the ICU stay and duration of hospitalization.

\section{Statistical methods and Result analysis:-}

The collected data were analyzed according to the objectives of the study. Descriptive (frequency and percentage distribution, mean and standard deviation) and inferential statistics (chi-square, chi-square with Yate's correction, ttest, odds ratio and relative risk) were used to analyze and interpret the primary data. Calculation was done using Microsoft excel and Statistical Package for Social Sciences (SPSS) 17.0.

Modified Clinical Pulmonary Infection Score (CPIS) is used to assist in the clinical diagnosis of ventilatorassociated pneumonia (VAP). SAPS II (Simplified Acute Physiology Score) is a severity of disease classification system (Le Gall, Lemeshow, Saulnier, 1993). It is a standardized tool that is designed to measure the severity of disease for the subjects. The difference between the two groups was considered as significant if $p<0.05$. Variables were expressed as mean $\pm \mathrm{SD}$ and frequency percentage.

\section{Ethical guidelines:-}

The institutional review board of the hospital approved the study for ethical issues. Written infoemed consent was obtained from the subjects or from their next of kin.

\section{Results:-}

\section{Patient characteristics:-}

The mean age of subjects was $48.40 \pm 1.70$ years. Both the selected groups were identical as per the patient's characteristics like age, gender. (Table I) Also, no statistically significant difference was observed among the subjects of two groups with respect to system involved in present illness, comorbidities. (Table I).

At admission, the SAPS II scores in ISSD group and SET group were homogenous ( $\mathrm{p}=0.352)$. Thus the severity of illness among the subjects of two groups admitted to intensive care units was similar (Table I). 
Table I:-Patient characteristics and clinical profile of subjects in ISSD and SET group.

$\mathbf{N}=\mathbf{1 3 0}$

\begin{tabular}{|c|c|c|c|}
\hline $\begin{array}{l}\text { Patients Characteristics/ } \\
\text { Clinical profile }\end{array}$ & ISSD group & SET group & p value \\
\hline Age (years) & $49.60 \pm 17.16$ & $47.13 \pm 17.01$ & $0.895^{\mathrm{NS}}$ \\
\hline $\begin{array}{c}\text { Gender } \\
\text { Male } \\
\text { Female }\end{array}$ & $\begin{array}{l}46(68.7) \\
21(31.3)\end{array}$ & $\begin{array}{l}43(68.3) \\
20(31.7)\end{array}$ & $0.960^{\mathrm{NS}}$ \\
\hline SAPS IIScores & $41.36 \pm 17.519$ & $44.13 \pm 16.157$ & $0.352^{\mathrm{NS}}$ \\
\hline $\begin{array}{l}\text { System involved in present illness } \\
\text { Central nervous } \\
\text { Endocrine } \\
\text { Gastrointestinal } \\
\text { Trauma } \\
\text { Renal } \\
\text { Respiratory } \\
\text { Others** } \\
\end{array}$ & $\begin{array}{l}23(34.3) \\
23(34.3) \\
14(20.9) \\
14(20.9) \\
10(14.9) \\
06(09.0) \\
08(11.9)\end{array}$ & $\begin{array}{l}25(39.7) \\
17(27.0) \\
16(25.4) \\
12(19.0) \\
10(15.9) \\
07(11.1) \\
17(27.0 .)\end{array}$ & $0.621^{\mathrm{NS}}$ \\
\hline $\begin{array}{l}\text { Co-morbidities }^{\S} \\
\text { Hypertension } \\
\text { Diabetes } \\
\text { CRF }\end{array}$ & $\begin{array}{l}23(34.3) \\
22(32.8) \\
07(10.4)\end{array}$ & $\begin{array}{l}20(31.7) \\
16(25.4) \\
03(04.8)\end{array}$ & $0.833^{\mathrm{NS}}$ \\
\hline $\begin{array}{c}\text { Medications } \\
\text { Antibiotics } \\
\text { Sedatives } \\
\end{array}$ & $\begin{array}{l}65(97.0) \\
47(70.1)\end{array}$ & $\begin{array}{l}63(100) \\
46(73.0)\end{array}$ & $\begin{array}{l}0.503^{\mathrm{NS}} \\
0.717^{\mathrm{NS}}\end{array}$ \\
\hline $\begin{array}{l}\mathrm{NS}=\text { Non Significant } \\
\text { Value in parentheses are percentages }\end{array}$ & & $\begin{array}{l}\text { systems are i1 } \\
\text { cological/ obs } \\
\text { patients mult }\end{array}$ & $\begin{array}{l}\text { patients } \\
\text { skeletal, Eye/ENT } \\
\text { ities were present }\end{array}$ \\
\hline
\end{tabular}

Subgroup analysis:-

Incidence of VAP was $23.6 \%$ (Figure 1) out of which $16.4 \%$ in ISSD group and $31.7 \%$ in SET group (p=0.04). (Figure 2) The relative risk of developing VAP in SET group as compared to ISSD group was 1.93 while odds of occurrence of VAP in SET group was about 2.37 times the odds of occurrence of VAP in ISSD group (R.R=1.93, OR 2.37, 95\% CI:1.009-3.705, $\mathrm{p}=0.04)$. (Table II) The incidence of early VAP onset was more in SET than ISSD group [23.8\% vs. 9.0\%, $(\mathrm{p}=0.039)]$. However no significant difference was found in the incidence of late VAP $[7.9 \%$ vs. $7.5 \%,(\mathrm{p}=0.92)]$ (Table III).

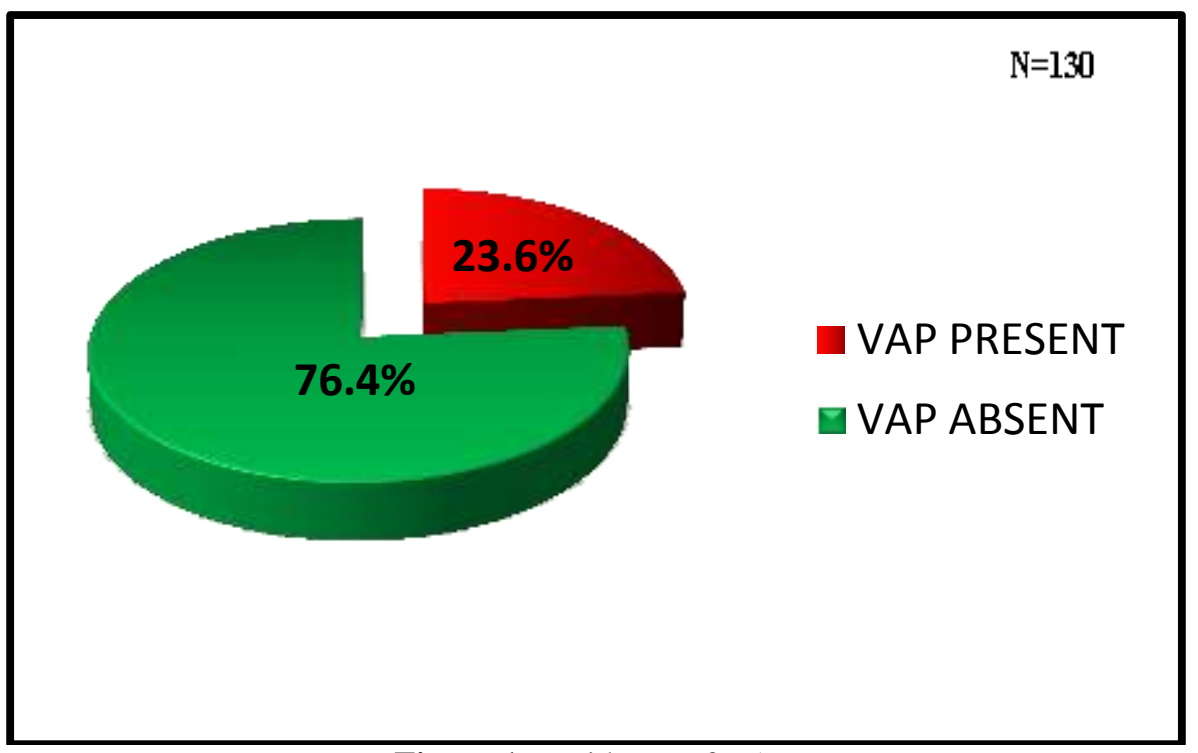

Figure 1:-Incidence of VAP 


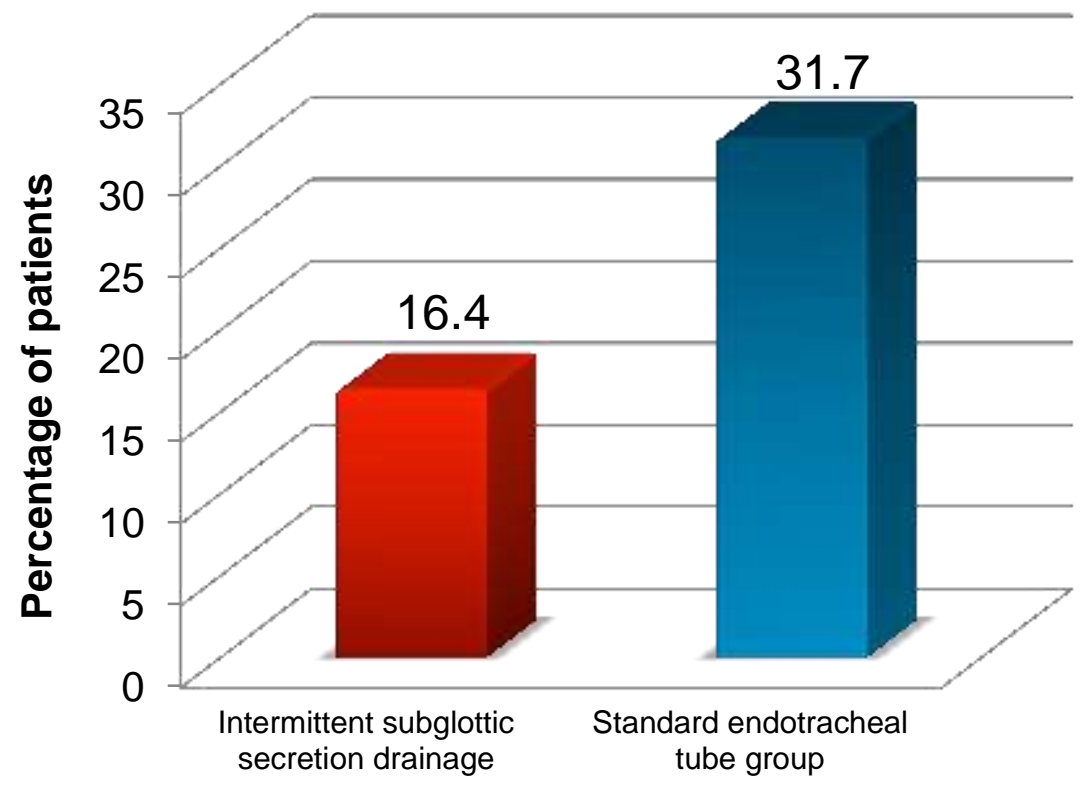

$\mathrm{N}=130$

Groups

Figure 2:-Comparison of incidence of VAP among two groups

Table II:-Association of incidence of VAP among ISSD and SET group

\begin{tabular}{|c|c|c|c|}
\hline \multirow[t]{2}{*}{ GROUPS } & \multicolumn{2}{|c|}{ VAP } & \multirow{3}{*}{$\begin{array}{c}\chi^{2}=4.20 \\
d f=1 \\
p=0.04\end{array}$} \\
\hline & $\begin{array}{c}\text { PRESENT } \\
\mathbf{f}(\%)\end{array}$ & $\begin{array}{c}\text { ABSENT } \\
\mathbf{f}(\%)\end{array}$ & \\
\hline $\begin{array}{l}\text { SET } \\
n=63\end{array}$ & $20(31.7)$ & $43(68.3)$ & \\
\hline $\begin{array}{l}\text { ISSD } \\
\mathrm{n}=67\end{array}$ & $11(16.4)$ & $56(83.6)$ & $\begin{array}{c}\text { R.R }=1.93 \\
\text { O.R. }=2.37 \\
\text { CI=1.00-3.70 } \\
\text { p=0.04* }\end{array}$ \\
\hline
\end{tabular}

Table III:-Incidence of VAP as per duration of onset among ISSD and SET group

$\mathbf{N}=\mathbf{1 3 0}$

\begin{tabular}{|l|c|c|c|}
\hline Incidence of VAP & $\begin{array}{c}\text { ISSD group } \\
\mathbf{f}(\boldsymbol{\%})\end{array}$ & $\begin{array}{c}\text { SET group } \\
\mathbf{f}(\boldsymbol{\%})\end{array}$ & p value \\
\hline VAP & $11(16.4)$ & $20(31.7)$ & $\mathbf{p = 0 . 0 4}^{*}$ \\
\hline Early VAP & $06(09.0 \%)$ & $15(23.8 \%)$ & $\mathbf{p = 0 . 0 3 9}$ \\
\hline Late VAP & $05(07.5 \%)$ & $05(07.9 \%)$ & $\mathrm{p}=0.92^{\mathrm{NS}}$ \\
\hline
\end{tabular}

The incidence density was lower among the ISSD than SET group respectively [23 vs. 41]. (Figure 3)

Outcome: No significant difference was found in the duration of hospitalization, length of the ICU stay, duration of intubation and duration of mechanical ventilation among subjects in ISSD group andSET group. Duration of ICU stay was $14.55 \pm 10.47$ days and $14.94 \pm 12.68$ days, respectively. Duration of mechanical ventilation was $07.09 \pm$ 3.70 and $07.63 \pm 4.70$ days, respectively (Table III).

As per the clinical outcome, the mortality even no significant difference was found ( $\mathrm{p}=0.984)$ (Table III). Also, as for reintubation $(\mathrm{p}=0.389)$ and tracheostomy, no statistically significant difference was observed in two group $(\mathrm{p}=0.401)$. (Table IV). Acinetobacter was the most common isolated micro-organism in ET secretion culture. (Table V). 
Table IV:-Baseline clinical outcome among subjects of ISSD and SET group. $\mathrm{MV}=$ Mechanical ventilation

NS $=$ Non Significant

$\mathbf{N}=\mathbf{1 3 0}$

Value in parentheses are percentages

\begin{tabular}{|l|c|c|l|}
\hline Clinical outcome & ISSD group & SET group & p value \\
\hline $\begin{array}{l}\text { Hospitalization } \\
\text { Duration (days) }\end{array}$ & $20.78 \pm 14.83$ & $20.22 \pm 14.56$ & $0.830^{\mathrm{NS}}$ \\
\hline ICU stay (days) & $14.55 \pm 10.47$ & $14.94 \pm 12.68$ & $0.850^{\mathrm{NS}}$ \\
\hline Duration of Intubation (days) & $07.85 \pm 4.19$ & $07.95 \pm 4.68$ & $0.896^{\mathrm{NS}}$ \\
\hline Duration of MV (days) & $07.09 \pm 3.70$ & $07.63 \pm 4.70$ & $0.466^{\mathrm{NS}}$ \\
\hline Mortality & $07(10.4)$ & $07(11.1)$ & $0.903^{\mathrm{NS}}$ \\
\hline Reintubation & $02(03.0)$ & $05(07.9)$ & $0.389^{\mathrm{NS}}$ \\
\hline Tracheostomy & $11(16.4)$ & $14(22.2)$ & $0.401^{\mathrm{NS}}$ \\
\hline
\end{tabular}

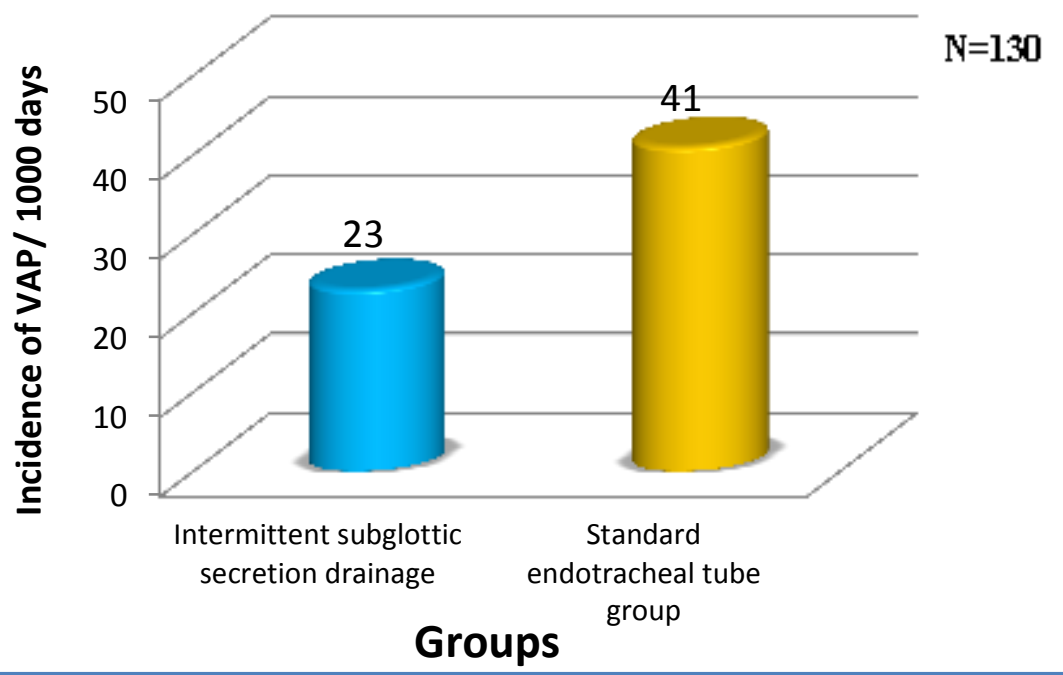

Figure 3:-Incidence density (VAP cases/1000 days of mechanical ventilation) in ISSD and SET group.

Table V:- Micro-organisms isolated in ET secretions in both groups during early and late VAP in both groups. $\mathbf{N}=31$

\begin{tabular}{|c|c|c|c|c|c|c|}
\hline \multirow[t]{2}{*}{$\begin{array}{l}\text { MICRO- } \\
\text { ORGANISM } \\
\text { ISOLATED }\end{array}$} & \multicolumn{3}{|c|}{$\begin{array}{c}\text { ISSD group } \\
\mathbf{n}=11 \\
\mathbf{f}(\%)\end{array}$} & \multicolumn{3}{|c|}{$\begin{array}{l}\text { SET } \\
\mathrm{n}=\mathbf{2 0} \\
\mathrm{f}(\%) \\
\end{array}$} \\
\hline & $\begin{array}{c}\text { Early VAP } \\
n_{1}=6\end{array}$ & $\begin{array}{c}\text { Late VAP } \\
n_{2}=5\end{array}$ & $\begin{array}{c}\text { Total } \\
\mathrm{n}=11 \\
\mathrm{f}\end{array}$ & $\begin{array}{l}\text { Early } \\
\text { VAP } \\
n_{1}=15\end{array}$ & $\begin{array}{c}\text { Late VAP } \\
\quad n_{2}=5\end{array}$ & $\begin{array}{c}\text { Total } \\
\mathrm{n}=\mathbf{2 0} \\
\mathrm{f}\end{array}$ \\
\hline Acinetobacter & $3(50.00)$ & $3(60.00)$ & 6 & $5(33.33)$ & $2(40.00)$ & 7 \\
\hline Pseudomonas & $3(50.00)$ & $1(20.00)$ & 4 & $3(20.00)$ & $1(20.00)$ & 4 \\
\hline Klebsiella & $1(16.67)$ & $1(20.00)$ & 2 & $3(20.00)$ & - & 3 \\
\hline Yeast-like cells & $1(16.67)$ & - & 1 & - & $1(20.00)$ & 1 \\
\hline Not known*** & $1(16.67)$ & $1(20.00)$ & 2 & $5(33.33)$ & $1(20.00)$ & 6 \\
\hline
\end{tabular}

\section{Discussion:-}

The present study assessed the overall incidence of VAP among the study subjects $(\mathrm{N}=130)$. In the present study it is found that out of the 130 subjects 31 were diagnosed with VAP. Thus the incidence of VAP was $23.8 \%$ with CPIS $\geq$ 6 which is in accordance Rit K. (2014)et al.who reported that out of the 140 selected patients $28(20 \%)$ of them were diagnosed with VAP with CPIS $>6$ and fulfilling microbiological criteria (in India). ${ }^{8}$ 
Present study reveals that the incidence-density of VAP was 32.4 per 1,000 ventilator days. This finding of the present study is very well supported by certain studies. Ranjan $\mathbf{N}$ et al. (2014) conducted a study in India, too concluded that the incidence density of VAP was 31.7/1000 ventilator days which was high but comparable to ICUs in other developing countries. ${ }^{9}$ Rodrigues DO et al. (2009) reported it as in a range of $10-52.7 / 1000$ days in developing countries. ${ }^{10}$ Also, Damas P et al. (2015) reported the monthly VAP rate ranging from 39.1 of 1,000 VD to 20 of $1,000 \mathrm{VD}^{11}$

In the present study, out of total 31 subjects who developed VAP, a higher percent of subjects i.e. $21(67.7 \%)$ were reported to have early onset (defined as development of VAP before 5 days of MV) than late onset (defined as development of VAP after 5 days of MV) VAP. The findings of the present study were also supported by a prospective study conducted by Reddy PSet al. (2013) in India. ${ }^{12}$

The main finding of the present study highlighted that the incidence of VAP is $31.7 \%$ in SET group which is quite twice than that of ISSD group i.e. $16.4 \%$ which was quite statistically significant difference $(\mathrm{p}=0.04)$. The results of a few meta-analysis on the randomized trials Barbas CSV et al. (2012) of subglottic drainage of secretions as compared to the usual care in adult mechanically ventilated ICU patients supported the findings of the present studyas it too showed that subglottic drainage of secretions was estimated to reduce the risk ${ }^{13}$ of VAP by $48 \%{ }^{5}$ Certain other studies conducted in Indian and Belgium settings tooreported that the ISSD results in reduction on incidence of $\mathrm{VAP}^{6,11}$ and the incidence density too. ${ }^{6}$ (Only a few studies are carried out in Indian setting.) But still there are certain studies which showed subglottic secretion drainage is not able to reduce the incidence of VAP significantly. ${ }^{14}$

In the present study, significant reduction in the incidence of early VAP onset was evident in ISSD group than SET [9.0\% vs. 23.8\%, ( $\mathrm{p}=0.039)]$. Contrasting result were stated by certain studies (Mao $\mathbf{Z}$ et al. (2016) as they concluded that the beneficial effect of SSD in reducing VAP was observed in both early-onset VAP and late-onset VAP. ${ }^{15}$ However, a few studies have shown similar results as our study whichtoo revealed that ISSD reduces the incidence of early-onset pneumonia. ${ }^{6,16}$

In certain earlier studies, ISSD has been shown to shorten the span of mechanical ventilation ${ }^{5}$ and also the duration of stay in ICUs. ${ }^{17,18}$. However in the present study, no significant reduction in hospital or ICU stays or days of mechanical ventilation or mortality was found with the use of ISSD. Similar results were obtained by few other studies who too did not find any reduction in the duration of MV and the length of stay in the intensive care unit. ${ }^{6,15}$ In our study we could not demonstrate any significant reduction in mortality as well. Still, there have been other studies as well that state that ISSD was not associated with reduced mortality. ${ }^{18,19,20,21}$ However Khorasani AG et al. (2016) stated strikingly different results as it concluded that the mortality rate was lesser in the case group. ${ }^{14}$

Our study concludes that the relative risk of developing VAP in SET group as compared to ISSD group was 1.93 while odds of occurrence of VAP in SET group was about 2.37 times the odds of occurrence of VAP in ISSD group.Similarly findings are shown by a Muscedere $\mathbf{J}$ et al. (2011) only who concludeda reduction of $50 \%$ in the risk of acquiring VAP (overall risk ratio, $0.55 ; 95 \% \mathrm{CI}, 0.46-0.66$ ) but no reduction in mortality. ${ }^{21}$

In this study Acinetobacter was the most common isolated micro-organism in the culture of the ET secretions of the subjects in both the groups irrespective of the duration of onset of VAP. No other study differentiated or specified the organism found among ISSD vs SET group in any setting. However, George $\mathbf{P}$ et al. (2010) studied antimicrobial sensitivity pattern among organisms which were isolated from the endotracheal aspirates of subjects with ventilator associated pneumonia concluded that the commonest organism isolated ET aspirate cultures were Acinetobacter, as seen in similar Indian studies. ${ }^{22}$

Even though the fact, that ISSD clears the secretions accumulated above the cuff of endotracheal tube and helps in reducing VAP, is well established and recommended by certain studies as one of an essential measure to prevent VAP, still it is not widely followed in the clinical practice especially in Indian scenario. Thus wider application of this evidence-based practice need to be advocated for more acceptances and also its application for the prevention of VAP in Indian critical care settings. 


\section{Limitations:-}

It was a single centre study. Also, longitudinal studies for longer duration are needed in order to investigate the effectiveness of ISSD vs SET on incidence of VAP. Blinding was difficult in such study among the observers related to the visual difference in ISSD and SET as ISSD ET is having a different cuff and a separate dorsal lumen. (However, most of the data collection was based on patient's records and reports and the attending physicians who established the diagnosis of VAP in documentation were not aware of the data being collected).

\section{Conclusion:-}

ISSD is beneficial as the incidence of VAP reduces by half as compared to Standard ET. ISSD also helps reducing early-onset VAP and incidence density.Therefore, it is recommended to use ISSD instead of standard ET tube to prevent VAP and it should be included as a part of VAP bundle in ICUs. Further RCTs are required to confirm our results.

\section{References:-}

1. Hoo GWS. Noninvasive Ventilation: overview. Available from: http://emedicine.medscape.com /article/304235-overview. Accessed on March 1, 2014.

2. DePew CL, McCarthy MS. Subglottic Secretion Drainage: A Literature Review. AACN Advanced Critical Care. 2007; 18(Pt 4) : 366-79.

3. Andre CK, Mark LM, Michael K, John M, Daniel AS, Lucy BP, et al. Management of Adults With Hospitalacquired and Ventilator-associated Pneumonia: 2016 Clinical Practice Guidelines by the Infectious Diseases Society of America and the American Thoracic Society. Clinical Infectious Diseases. 2016; 63(Pt 5) : 61-111.

4. Amanullah S. Ventilator-associated and hospital-acquired pneumonia Overview of Nosocomial Pneumonias: 2013. Available from: http://emedicine.medscape.com/ article/304836-overview, Accessed on March 1, 2014.

5. Frost SA, Azeem A, Alexandrou E, Tam V, Murphy JK, Hunt L, et al. Subglottic secretion drainage for preventing ventilator associated pneumonia: A meta-analysis. Australian Critical Care. 2013; 26(Pt 4) : 180-8.

6. Juneja D, Javeri Y, Singh O, Nasa P, Pandey R, Uniyal B. Comparing influence of intermittent subglottic secretions drainage with/without closed suction systems on the incidence of ventilator associated pneumonia. Indian Journal of Critical Care Medicine. 2011; 15(Pt 3) : 168-72.

7. American Thoracic Society, Infectious Diseases Society of America. Guidelines for the management of adults with hospital-acquired, ventilator-associated, and healthcare-associated pneumonia. Am. J. Respir. Crit. Care Med. 2005; $171: 388-416$.

8. Rit K, Chakraborty B, Saha R, Majumder U. Ventilator associated pneumonia in a tertiary care hospital in India: Incidence, etiology, risk factors, role of multidrug resistant pathogens. International Journal of Medicine and Public Health. 2014; 4(Pt 1): 51.

9. Ranjan N, Chaudhary U, Chaudhry D, Ranjan KP. Ventilator-associated pneumonia in a tertiary care intensive care unit: Analysis of incidence, risk factors and mortality. Indian journal of critical care medicine. 2014; 18(Pt 4):200-4.

10. Rodrigues DO, Cezário RC, Filho PPG. Ventilator-Associated Pneumonia (VAP) caused by MultidrugResistant (MDR) Pseudomonas aeruginosa vs. other microorganisms at an adult clinical-surgical intensive care unit in a Brazilian University Hospital: Risk factors and outcomes. International Journal of Medicine and Medical Sciences. 2009; 1(Pt 10): 432-37.

11. Damas P, Frippiat F, Ancion A, Canivet JL, Lambermont B, Layios N et al. Prevention of VentilatorAssociated Pneumonia and Ventilator-Associated Conditions: A Randomized Controlled Trial with Subglottic Secretion Suctioning. Critical care medicine. 2015; 43(Pt 1) : 22-30.

12. Reddy PS, Athuluri V, Kumar SS. Incidence of ventilator associated pneumonia. Journal of Microbiology and Biotechnology Research. 2013; 3(Pt 1) : 1-4.

13. Barbas CSV, Couto LP. Do endotracheal tubes with suction above the cuff decrease the rate of ventilatorassociated pneumonia, and are they cost-effective? RevistaBrasileira de TerapiaIntensiva. 2012; 24(Pt 4) :32021.

14. Khorasani AG, Shadnia S, Mashayekhian M, Rahimi M, Aghabiklooei A. Efficacy of Hi-Lo Evac Endotracheal Tube in Prevention of Ventilator-Associated Pneumonia in Mechanically Ventilated Poisoned Patients. Scientifica. 2016 (Pt 2016).

15. Lacherade JC, De Jonghe B, Guezennec P,Debbat K, Hayon J, Monsel A et al. Intermittent subglottic secretion drainage and ventilator-associated pneumonia: a multicenter trial. American journal of respiratory and critical care medicine. 2010; 182(Pt 7) : 910-17. 
16. Mao Z, Gao L, Wang G, Liu C, Zhao Y, Gu W, et al. Subglottic secretion suction for preventing ventilatorassociated pneumonia: an updated meta-analysis and trial sequential analysis. Crit Care. 2016; 20(Pt 1): 353.

17. Dezfulian C, Shojania K, Collard HR, Kim HM, Matthay MA, Saint S. Subglottic secretion drainage for preventing ventilator-associated pneumonia: A meta-analysis. Am J Med. 2005; 118:11-8. [PubMed]

18. Wang R, Zhen X, Yang BY, Guo XZ, Zeng X, Deng CY. Subglottic secretion drainage for preventing ventilator associated pneumonia: A meta-analysis. Chinese Nursing Research. 2015; 2(Pt 2-3), 55-60.

19. Bouza E, Pérez MJ, Muñoz P, Rincón C, Barrio JM, Hortal J. Continuous aspiration of subglottic secretions in the prevention of ventilator-associated pneumonia in the postoperative period of major heart surgery. Chest. 2008; 134: 938-46.

20. Smulders K, van der Hoeven H, Weers-Pothoff I, Vandenbroucke-Grauls C. A randomized clinical trial of intermittent subglottic secretion drainage in patients receiving mechanical ventilation. Chest. 2002; 121: 85862 .

21. Muscedere J, Rewa O, McKechnie K, Jiang X, Laporta D, Heyland DK. Subglottic secretion drainage for the prevention of ventilator-associated pneumonia: A systematic review and meta-analysis. Critical care medicine. 2011; 39(Pt 8) : 1985-91.

22. George P, Sequiera A. Antimicrobial sensitivity pattern among organisms which were isolated from the endotracheal aspirates of patients with ventilator associated pneumonia. J ClinDiag Res. 2010; 4 : 3397-401.

23. Krein SL, Kowalski CP, Damschroder L, Forman J, Kaufman SR, Saint S. Preventing ventilator-associated pneumonia in the United States: A multicenter mixed-methods study. Infect Control HospEpidemiol. 2008; 29 : 933-40. 